\title{
H2O2/ABA signal pathway participates in the regulation of stomata opening of cucumber leaves under salt stress by putrescine
}

\author{
Siguang Ma ${ }^{1}$, M. Shah Jahan ${ }^{2}$, Shi Rong Guo ${ }^{3}$, Mimi Tian ${ }^{1}$, Ranran Zhou ${ }^{1}$, Hongyuan \\ $\mathrm{Liu}^{1}$, Bingjie Feng ${ }^{1}$, and Sheng Shu ${ }^{1}$ \\ ${ }^{1}$ Nanjing Agricultural University - Weigang Campus \\ ${ }^{2}$ Nanjing Agricultural University \\ ${ }^{3}$ Affiliation not available
}

September 16, 2020

\begin{abstract}
The stomatal-aperture is imperative for plant physiological metabolism. The function of polyamines (PAs) in stomatal regulation under stress environment largely remains elucidate. Herein, we investigated the regulatory mechanism of exogenous putrescine (Put) on the stomatal opening of cucumber leaves under salt stress. The results revealed that Put relieved the salt-induced photosynthetic inhibition of cucumber leaves by regulating stomatal-apertures. Put application increased hydrogen peroxide ( $\mathrm{H} 2 \mathrm{O} 2)$ and decreased abscisic acid (ABA) content in leaves under salt stress. The inhibitors of diamine oxidase (DAO), polyamine oxidase (PAO), nicotinamide adenine dinucleotide phosphate oxidase (NADPH) are AG, 1,8-DO and DPI, respectively and pre-treatment with these inhibitors up-regulated key gene NCED of ABA synthase and down-regulated key gene GSHS of reduced glutathione (GSH) synthase. The content of $\mathrm{H} 2 \mathrm{O} 2$ and GSH were decreased and ABA content was increased and its influenced trend is AG $>1,8-\mathrm{DO}>\mathrm{DPI}$. Moreover, the Put induced down-regulation of ABA content under salt stress blocked by treatment with $\mathrm{H} 2 \mathrm{O} 2$ scavenger (DMTU) and GSH scavenger (CNDB). Additionally, the application of DMTU also blocked the increase of GSH content. Collectively, these results suggest that Put can regulate GSH content by promoting $\mathrm{H} 2 \mathrm{O} 2$ generation through polyamine metabolic pathway, which inhibits ABA accumulation to achieve stomatal regulation under salt stress.
\end{abstract}

\section{Hosted file}

Manuscript -.doc available at https://authorea.com/users/359205/articles/481379-h2o2-abasignal-pathway-participates-in-the-regulation-of-stomata-opening-of-cucumber-leavesunder-salt-stress-by-putrescine

\section{Hosted file}

Figures.doc available at https://authorea.com/users/359205/articles/481379-h2o2-aba-signalpathway-participates-in-the-regulation-of-stomata-opening-of-cucumber-leaves-under-saltstress-by-putrescine

\section{Hosted file}

Supplementary Figures S1-S3+Tables S1.doc available at https://authorea.com/users/359205/ articles/481379-h2o2-aba-signal-pathway-participates-in-the-regulation-of-stomataopening-of-cucumber-leaves-under-salt-stress-by-putrescine 